\title{
EFFECT OF Re AND Ta ON HOT CORROSION RESISTANCE OF NICKEL-BASE SINGLE CRYSTAL SUPERALLOYS
}

\author{
J.X. Chang, D. Wang, G. Zhang, L.H. Lou, J. Zhang \\ Superalloys Division, Institute of Metal Research, Chinese Academy of Sciences, 72 Wenhua Road, Shenyang 110016, China
}

\author{
Keywords: Hot Corrosion, Molten Salts, Rhenium, Tantalum, Sulfidation
}

\begin{abstract}
Hot corrosion behavior of several Ni-base single crystal (SX) superalloys with different $\mathrm{Re}$, Ta and $\mathrm{Cr}$ contents at $750{ }^{\circ} \mathrm{C}$ and $900{ }^{\circ} \mathrm{C}$ in static air has been systematically investigated using the "deposit recoat" method. It was shown that, both Re and Ta can improve the hot corrosion resistance of SX superalloys. Re may alter the activities of elements and therefore delay the deformation and cracking of oxide scale, and may enable the self-healing of the oxide scale. The advantage to hot corrosion properties of adding $\mathrm{Ta}$ depends on $\mathrm{Cr}$ content in the superalloys. The beneficial effect of Ta is more pronounced in alloys with a low $\mathrm{Cr}$ content. Ta was found to exhibit a beneficial effect by promoting the formation of $\mathrm{NaTaO}_{3}$ and $\mathrm{TaS}_{2}$, and therefore inhibiting the formation of liquid $\mathrm{Na}_{2} \mathrm{MoO}_{4}$ and Ni-sulfides. It seems that Re and $\mathrm{Ta}$ are promising elements that allow us to design hot corrosion resistant superalloys with superior high temperature properties.
\end{abstract}

\section{Introduction}

Hot corrosion resistant superalloys are extensively used in industrial gas turbines (IGTs) because of their outstanding mechanical strength and hot corrosion resistance. In order to improve the inlet temperature of IGTs, much effort has been made to improve the high temperature strength of the hot corrosion resistant superalloys. Generally, around $12-16 \mathrm{wt} . \% \mathrm{Cr}$ along with at least 3 wt. $\% \mathrm{Ti}$ is required for acceptable hot corrosion resistance [1-4]. However, a high $\mathrm{Cr}$ content limits the potential to use more refractory elements ( $\mathrm{Re}, \mathrm{Mo}, \mathrm{W}$ and $\mathrm{Ta}$ ) to further improve the mechanical strength of the alloys, i.e., one needs to balance the hot corrosion resistance, high temperature strength and microstructural stability carefully during alloy design.

As revealed by previous researchers, $\mathrm{W}$ and Mo show detrimental effects on hot corrosion resistance, because their acid oxides can accelerate the corrosion rate dramatically [5-7]. Re and Ta may be the choices for stronger alloys, but very limited information is available regarding their effects on the hot corrosion resistance and mechanism, especially in alloys with low $\mathrm{Cr}$ content.

Matsugi and coworkers [8-10] have investigated the effect of Re on hot corrosion behavior and clearly showed that the hot corrosion resistance was improved remarkably by small Re additions, though the sample analysis and mechanism were not given. Caron and Czech also reported the same effect $[11,12]$. They regarded the effect of Re as being a diffusion barrier of the reactive elements. But, there is no corresponding experimental evidence. Gurrappa [13] has observed Re-containing products in hot-corroded samples of CMSX-4. They explained the hot corrosion behavior of the alloy as electrochemical in nature. However, role of Re was not mentioned. Therefore, further investigation was needed to better understand the mechanism of Re on hot corrosion resistance.
Fryburg [14-16] has studied the hot corrosion behavior of several Ni-base superalloys and concluded that Ta improved the hot corrosion resistance by facilitating the formation of solid $\mathrm{NaTaO}_{3}$ and suppressing the formation of liquid $\mathrm{Na}_{2} \mathrm{Mo}(\mathrm{W}) \mathrm{O}_{4}$. It has been reported that a better hot corrosion resistance would be obtained if the $\mathrm{Ta} /(\mathrm{Mo}+\mathrm{W})$ compositional ratio is close to unity in the alloy $[10,17]$. In our previous work [18], beneficial effect of Ta was also observed. It seems that $\mathrm{Ta}$ promoted the formation of $\mathrm{NaTaO}_{3}$ and $(\mathrm{Cr}, \mathrm{Ti}) \mathrm{TaO}_{4}$, with the latter spinel phase acting as a diffusion barrier of ions. However, results acquired by Zhang [19] and Cui [20] demonstrated that Ta deteriorated the hot corrosion resistance, for reasons unstated. Currently, most work studying the effect of elements on hot corrosion resistance focuses on the formation of oxygen-containing oxides or spinels, such as $\mathrm{Cr}_{2} \mathrm{O}_{3}$ $[21,22], \mathrm{NaTaO}_{3}[14,15]$ and $(\mathrm{Cr}, \mathrm{Ti}) \mathrm{TaO}_{4}$ [18], while the formation of sulfides that may dramatically affect the corrosion mechanisms [23] has not been monitored.

The aim of our present paper is to study the effect of Re and Ta on hot corrosion behavior of SX Ni-base superalloys with different $\mathrm{Cr}$ contents, trying to analyze the corrosion mechanism and provide new perspective in alloy design for high strength hot corrosion resistant SX superalloys.

\section{Experimental}

Nominal chemical compositions of the experimental alloys are listed in table 1 . The experimental alloys were divided into three groups to conduct hot corrosion test: (I) E1 (12Cr-0Re) and E7 (12Cr-2Re); (II) E7 (12Cr-2Re-4Ta) and E71 (12Cr-2Re-6Ta); (III): E74 (5Cr-6Ta) and E76 (5Cr-9Ta), with contents of other elements identical in each group.

SX rods of the experimental alloys measuring $16 \mathrm{~mm}$ in diameter and $220 \mathrm{~mm}$ in length were fabricated by high rate solidification (HRS) method. All rods received proper heat treatment. Hot corrosion specimens were cut from as heat-treated rods. The surfaces of the samples were prepared by grinding on $\mathrm{SiC}$ paper to \#800 and all the samples were chamfered before test. Ultrasonic clean with acetone and alcohol was performed after all the preparation processes.

Hot corrosion test was carried out at $750{ }^{\circ} \mathrm{C}$ and $900{ }^{\circ} \mathrm{C}$. The salt-recoating method, which has been described in detail in our previous paper [24], was employed in the experiments. Specimens were placed on a hot Ni plate and sprayed with saturated aqueous solution of $\mathrm{Na}_{2} \mathrm{SO}_{4}$ until their surfaces were coated with $0.3 \sim 0.5$ $\mathrm{mg} / \mathrm{cm}^{2}$ salt. The sprayed specimens were put into separated corundum crucibles and placed in static air at 1 atm at test temperature to perform the hot corrosion test. The test was periodically interrupted every $20 \mathrm{~h}$ and the samples were removed from the furnace for weight monitoring and salt-recoating. The time interval between being taken out and weighted was $1 \mathrm{~h}$ in 
every cycle. Each data point of the mass change was the average of three samples.

Scanning electron microscopy (SEM) equipped with an energy dispersive spectroscopy (EDS), electro-probe microanalyser
(EPMA) and X-ray diffraction (XRD) were used to characterize the microstructure and to identify the corrosion products. To prevent dissolving the water soluble corrosion products into water, all the cross-sectioned samples were ground and polished in kerosene [14].

Table 1 Nominal chemical compositions of the experimental alloys in wt.\%.

\begin{tabular}{ccccccccccc}
\hline Alloy & Cr & Co & Mo & W & Ti & Al & Ta & Re & Ni \\
\hline E1 & 12.00 & 9.00 & 1.90 & 4.00 & 3.90 & 3.40 & 4.00 & Bal. \\
E7 & 12.00 & 9.00 & 1.90 & 4.00 & 3.90 & 3.40 & 4.00 & 2.00 & Bal. \\
E71 & 12.00 & 9.00 & 1.90 & 4.00 & 3.90 & 3.40 & 6.00 & 2.00 & Bal. \\
E74 & 5.00 & 10.00 & 2.00 & 6.00 & - & 5.50 & 6.00 & 3.00 & Bal. \\
E76 & 5.00 & 10.00 & 2.00 & 6.00 & - & 5.50 & 9.00 & 3.00 & Bal. \\
\hline
\end{tabular}

\section{Results}

\section{Hot Corrosion Resistance and Products at $750{ }^{\circ} \mathrm{C}$}

The three groups of samples were put together to conduct the hot corrosion test at $750{ }^{\circ} \mathrm{C}$. Here we only show a representative macroscopic appearance of the samples corroded for $200 \mathrm{~h}$ in Fig. 1 , due to the observation that the morphologies of all the samples were similar during the whole test. The sprayed salt still can be seen and the sample was still complete.

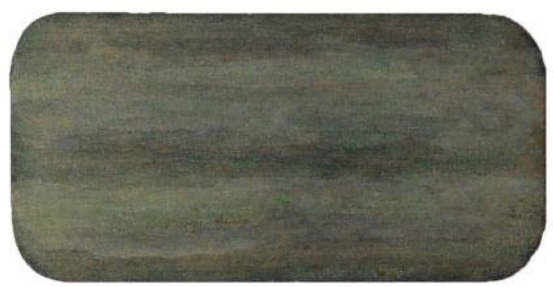

Figure 1 Macroscopic appearance of the samples corroded for $200 \mathrm{~h}$ at $750{ }^{\circ} \mathrm{C}$.
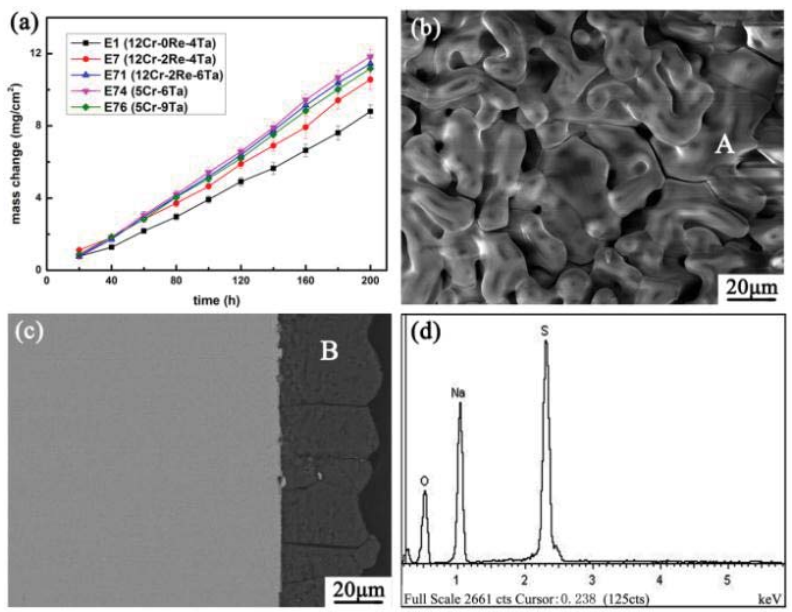

Figure 2 (a) Weight gain versus time curves for the experimental alloys with a surface coating of $\mathrm{Na}_{2} \mathrm{SO}_{4}$ at $750{ }^{\circ} \mathrm{C}$. (b) and (c): Representative surface and cross-section morphologies of the samples corroded for $200 \mathrm{~h}$ at $750{ }^{\circ} \mathrm{C}$. (d) EDS result of point A and $\mathrm{B}$ in (b) and (c).

Weight gain versus time curves for the experimental alloys are shown in Fig. 2a. The mass change of all alloys followed the linear law. Representative surface and cross-section morphologies of the samples corroded for $200 \mathrm{~h}$ are illustrated in Fig. $2 \mathrm{~b}$ and 2c.
The surfaces of the samples were covered by pure condensed $\mathrm{Na}_{2} \mathrm{SO}_{4}$, as was confirmed by EDS (Fig. 2d). The interface of the substrate and the salt coating was smooth and flat (Fig. 2c).

\section{Hot Corrosion Resistance and Products at $900^{\circ} \mathrm{C}$}

Re Effect Hot corrosion kinetics of group I alloys are shown in Fig. 3. It can be seen that, the mass change of the two alloys were similar in the initial $100 \mathrm{~h}$. Both curves followed parabolic law. After $100 \mathrm{~h}$, corrosion kinetics of the Re-free alloy changed. E1 experienced rapid mass change in the last $100 \mathrm{~h}$. The overall corrosion kinetics of the Re-containing alloy followed multi-stage parabolic law and the inflection points were $320 \mathrm{~h}$ and $400 \mathrm{~h}$. The mass of E7 increased slowly during the whole test.

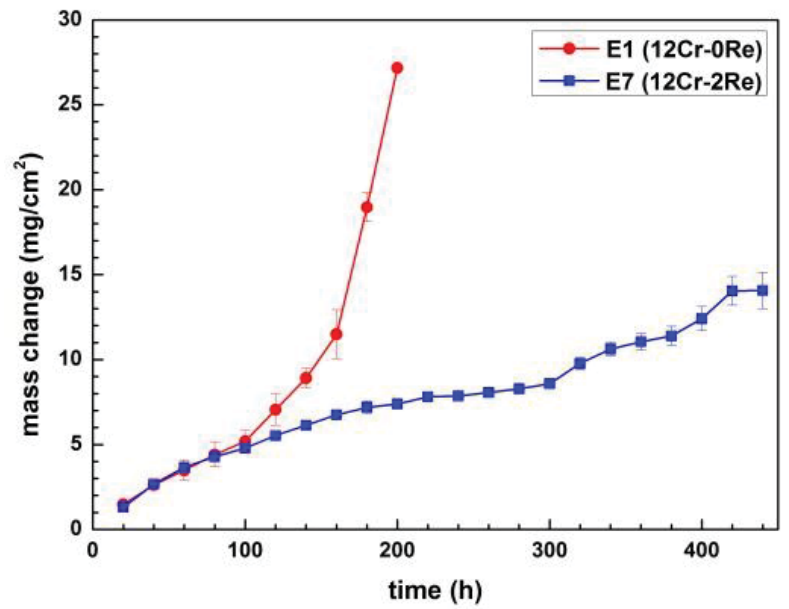

Figure 3 Weight gain versus time curves for group I alloys with a surface coating of $\mathrm{Na}_{2} \mathrm{SO}_{4}$ at $900{ }^{\circ} \mathrm{C}$.

The macroscopic morphologies of the group I alloys corroded at $900{ }^{\circ} \mathrm{C}$ is given in Fig. 4. After $20 \mathrm{~h}$ corrosion, the surfaces of both alloys became black, but they were still flat and complete (Fig. 4a and 4d). As of $100 \mathrm{~h}$, the surfaces of E1 samples were covered with small protrusions (Fig. 4b), while the time that protrusions appeared on E7 was $160 \mathrm{~h}$ (Fig. 4e and 4f). After protrusions occurred, the oxide scale on E1 became extremely fragile and started to crack and spall off. As of $200 \mathrm{~h}$, the E1 sample was severely damaged. Cracking and spallation was remarkable (Fig. 4c). However, the E7 samples were nearly unchanged after the protrusions appeared. Until $440 \mathrm{~h}$, the E7 samples were still compact and complete. 

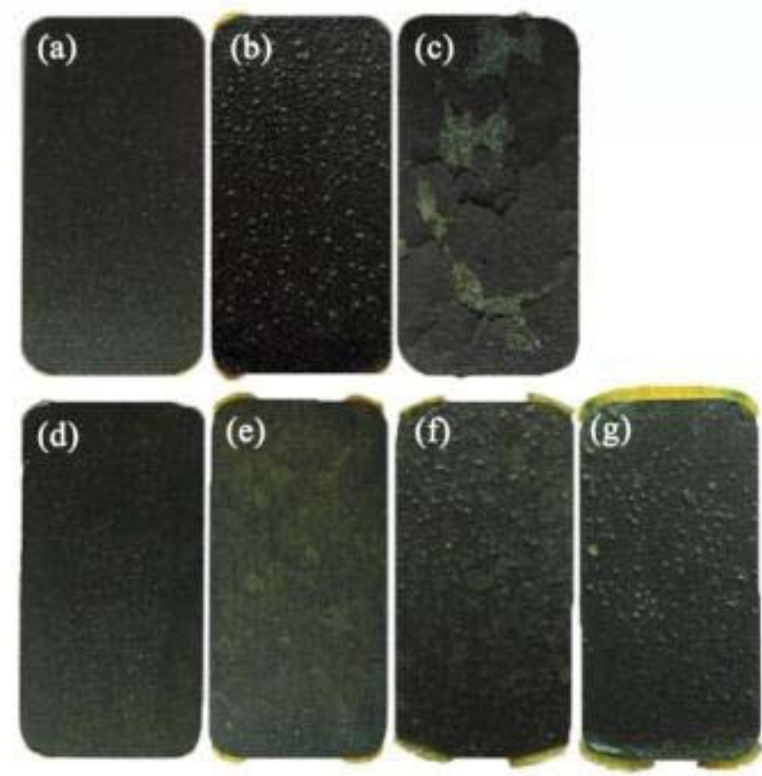

Figure 4 Macroscopic morphologies of the group I alloys corroded at $900{ }^{\circ} \mathrm{C}$ with a surface coating of $\mathrm{Na}_{2} \mathrm{SO}_{4}$. (a) $\mathrm{E} 1$ for 20 h. (b) E1 for 100 h. (c) E1 for 200 h. (d) E7 for 20 h. (e) E7 for $100 \mathrm{~h}$. (f) E7 for $160 \mathrm{~h}$. (g) E7 for $440 \mathrm{~h}$.

The cross-section morphologies of E1 are illustrated in Fig. 5, in which the phases were identified according to the EDS and XRD analyses (When comparing the cross-section morphologies of
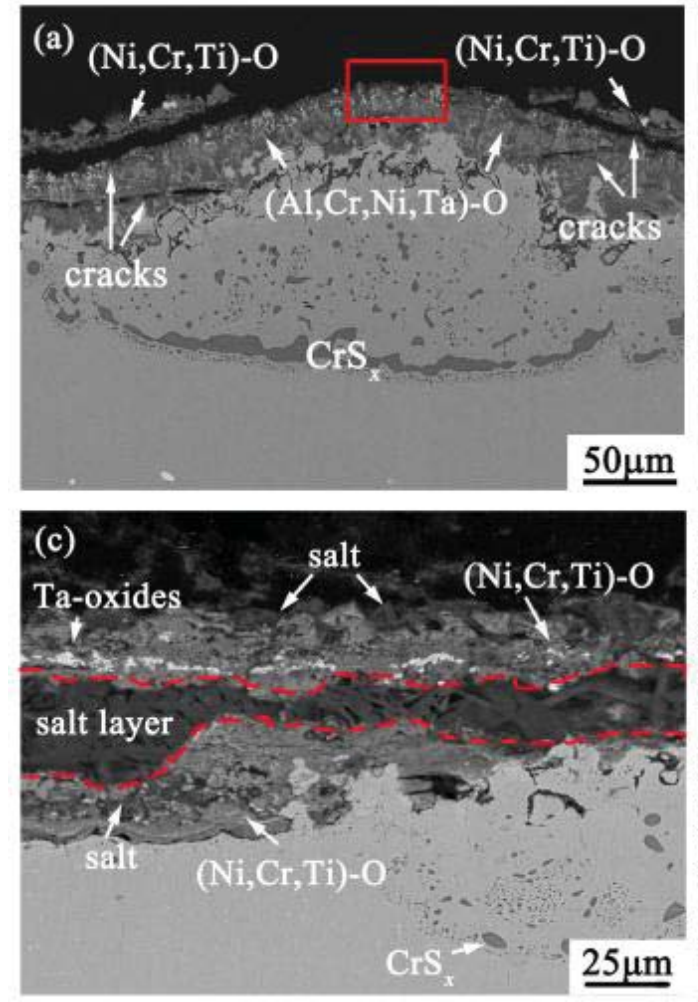

protrusions on E1 and E7, we removed the residual salt on the samples.). The morphology of the protrusion on E1 at $100 \mathrm{~h}$ is given in Fig. 5a. The outer layer of the protrusion was (Ni,Cr,Ti)-O oxides. At the tip of the protrusion, the outer oxide layer spalled off. The sub-surface layer was mixed oxides of Al, $\mathrm{Cr}$, Ni and Ta. Cracks parallel to and perpendicular to the surface of the protrusion can be seen (Fig. $5 \mathrm{a}$ and $5 \mathrm{~b}$ ). The inner sulfide layer was almost continuous. Molten salt penetrated the outer oxide layer at $120 \mathrm{~h}$ (Fig. 5c). A continuous and compact salt layer can be seen at the middle of the oxide layer. As of $200 \mathrm{~h}$, both the salt layers and the $\mathrm{NiO}$ layers became loose and porous (Fig. 5d). Dissolved $\mathrm{NiO}$ grains dispersed in the honeycomb salt layer. (Al,Ni,Cr)-O oxide network extended into the substrate. $\mathrm{CrS}_{x(1.000<x<1.500)}$ particles can be seen in the front of the corrosion layer (The stable phases in $\mathrm{Cr}-\mathrm{S}$ system can be denoted as $\mathrm{CrS}_{x}$, with $1.000<x<1.500$ [25].).

The cross-section morphologies of E7 are presented in Fig. 6. The outer $(\mathrm{Cr}, \mathrm{Ni}, \mathrm{Ti})-\mathrm{O}$ oxide layer was still complete and compact at 200 h. A continuous residual salt layer can be seen at the outermost of the sample surface. The inner $\mathrm{Al}_{2} \mathrm{O}_{3}$ layer was almost continuous. The cross-section morphology of the protrusion formed on E7 at $440 \mathrm{~h}$ is given in Fig. $6 \mathrm{~b}$ (The sample was washed by boiling water for comparison with E1.). The (Cr,Ni,Ti)-O oxide layer on protrusions was still integrate after $440 \mathrm{~h}$. The amount of the inner sulfides was much less than that in $\mathrm{E} 1 \mathrm{at} 100 \mathrm{~h}$. Cracks and holes can be seen.

Figure 5 (a) Cross-section morphology of protrusion on E1 at $100 \mathrm{~h}$. (b) Higher magnification of the rectangle area in (a). (c) Typical cross-section morphology of flat region on E1 at $120 \mathrm{~h}$. (d) Typical cross-section morphology of E1 at $200 \mathrm{~h}$. 


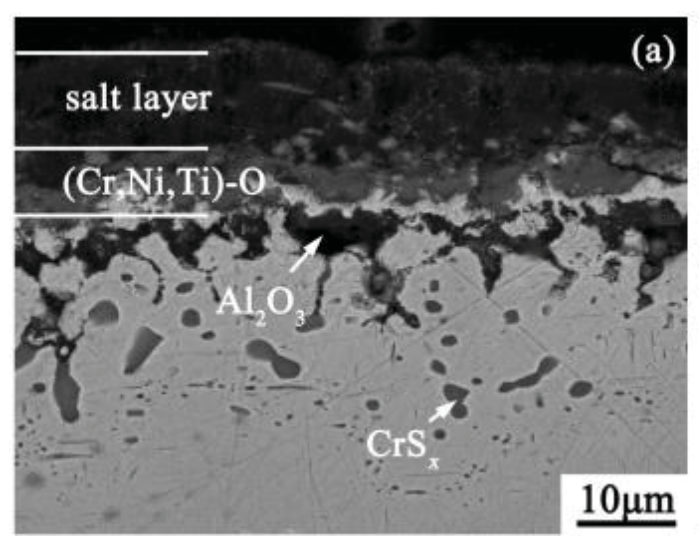

Figure 6 (a) Typical cross-section morphology of E7 at $200 \mathrm{~h}$.

Ta Effect in High Cr Alloys Hot corrosion kinetics of group II alloys at $900{ }^{\circ} \mathrm{C}$ are given in Fig. 7. The corrosion kinetics of E7 (12Cr-2Re-4Ta) and E71 (12Cr-2Re-6Ta) were similar, both of the two alloys followed multi-stage parabolic law (The group I and group II were conducted as two individual tests. Differences found in Fig. 3 and Fig. 7 for E7 were probably due to the differences in the salt amount or its uniformity in the two tests.).

The macroscopic appearances of the group II alloys corroded for $240 \mathrm{~h}$ at $900{ }^{\circ} \mathrm{C}$ are shown in Fig. 8. After $240 \mathrm{~h}$ corrosion, the two samples were still compact and complete. Yellow products can be seen on their surfaces.

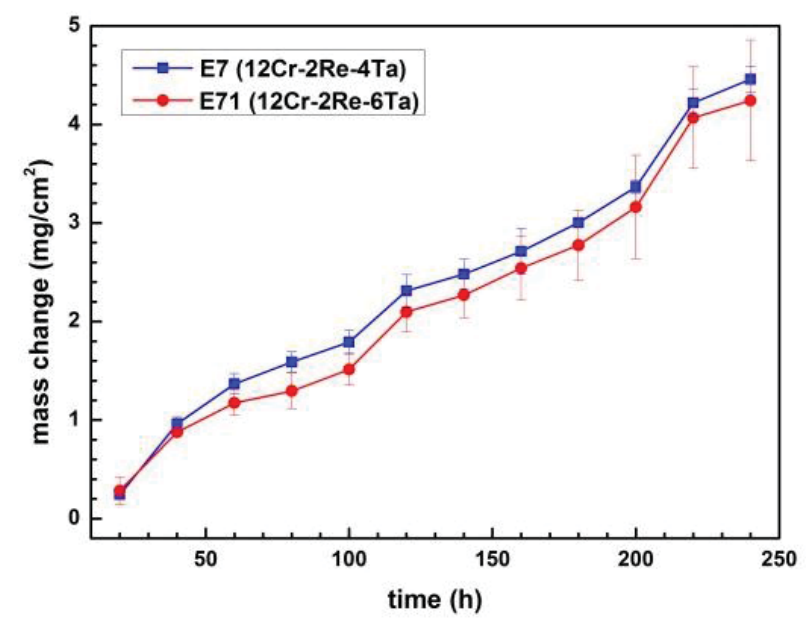

Figure 7 Weight gain versus time curves for group II alloys with a surface coating of $\mathrm{Na}_{2} \mathrm{SO}_{4}$ at $900{ }^{\circ} \mathrm{C}$.

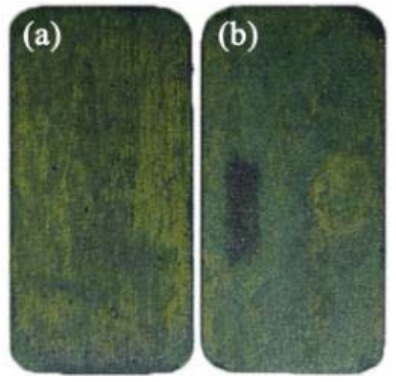

Figure 8 Macroscopic appearances of the group II alloys corroded for $240 \mathrm{~h}$ at $900{ }^{\circ} \mathrm{C}$ with a surface coating of $\mathrm{Na}_{2} \mathrm{SO}_{4}$. (a) E7. (b) E71.

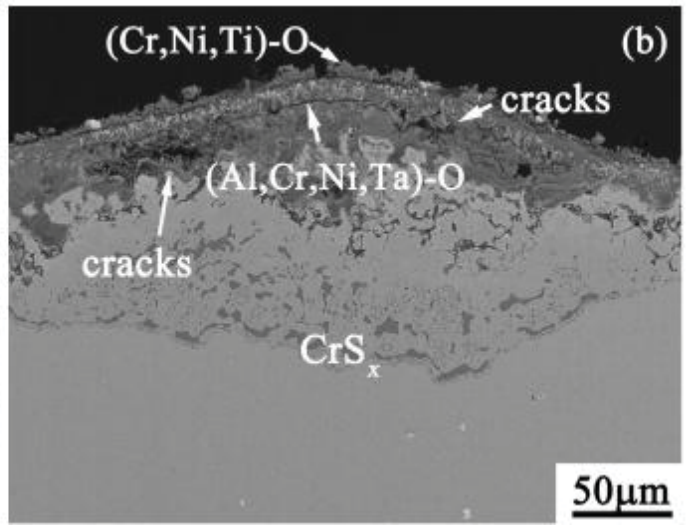

. (b) Cross-section morphology of protrusion on E7 at $440 \mathrm{~h}$.

XRD results of the samples corroded for $20 \mathrm{~h}$ and $240 \mathrm{~h}$ are illustrated in Fig. 9. After $20 \mathrm{~h}$ corrosion, the main products on E7 were $\mathrm{Cr}_{2} \mathrm{O}_{3}, \mathrm{TiO}_{2}$ and spinels. While for E71, Ta-containing products $\mathrm{TaO}_{2}$ and $\mathrm{TiTaO}_{4}$ were detected besides $\mathrm{Cr}_{2} \mathrm{O}_{3}, \mathrm{TiO}_{2}$ and spinels. As of $240 \mathrm{~h}$, the phases detected on E7 and E71 were similar. The main constituent of their corrosion scales were $\mathrm{Cr}_{2} \mathrm{O}_{3}$, $\mathrm{Na}_{2} \mathrm{Cr}_{2} \mathrm{Ti}_{6} \mathrm{O}_{16}$ and residual salt.

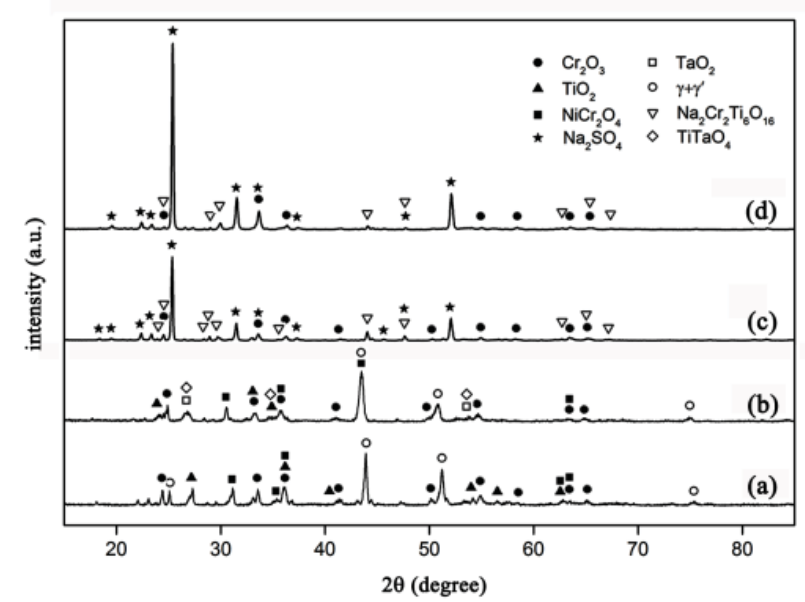

Figure $9 \mathrm{XRD}$ results of the group II samples with different corrosion time. (a) E7 for $20 \mathrm{~h}$. (b) E71 for $20 \mathrm{~h}$. (c) E7 for $240 \mathrm{~h}$. (d) E71 for $240 \mathrm{~h}$.

Surface morphologies and EDS analyses of the corrosion scales formed after $240 \mathrm{~h}$ exposure at $900{ }^{\circ} \mathrm{C}$ are presented in Fig. 10. The surface morphologies of E7 and E71 were similar. Their surfaces were covered by a condensed salt film (mark as " $A$ " in Fig. 10). Cracks were produced because of cooling and surface tension. EDS analysis of the salt film (Fig. 10c) indicated that the salt wasn't the initially sprayed pure sodium sulfate. Chromate and titanate, which were probably introduced by the dissolution of the corresponding oxides, were also a part of the salt film. Besides the salt film, a white needle-like phase (marked as "B" in Fig. 10) containing $\mathrm{Na}, \mathrm{Cr}$, Ti and $\mathrm{O}$ (Fig. 10d) was observed, with its amount on E71 more than on E7.

Cross-section morphologies of the corrosion scales are given in Fig. 11. After $20 \mathrm{~h}$ exposure, the structures of the corrosion scales formed on the two alloys were similar. They consisted of an outer oxide layer, an inner $\mathrm{Al}_{2} \mathrm{O}_{3}$ layer and a sulfide layer. The dominant constituents of the outer layer were $\mathrm{Cr}$ - and 
Ti-containing oxides and spinels. White phases enriching in Ta can be observed in E71. As of $240 \mathrm{~h}$, the structures of the corrosion scales on E7 and E71 were almost unvaried, excepting the outermost thick salt layer. $\mathrm{Cr}_{2} \mathrm{O}_{3}$ was the main products on $\mathrm{E} 7$ and E71.

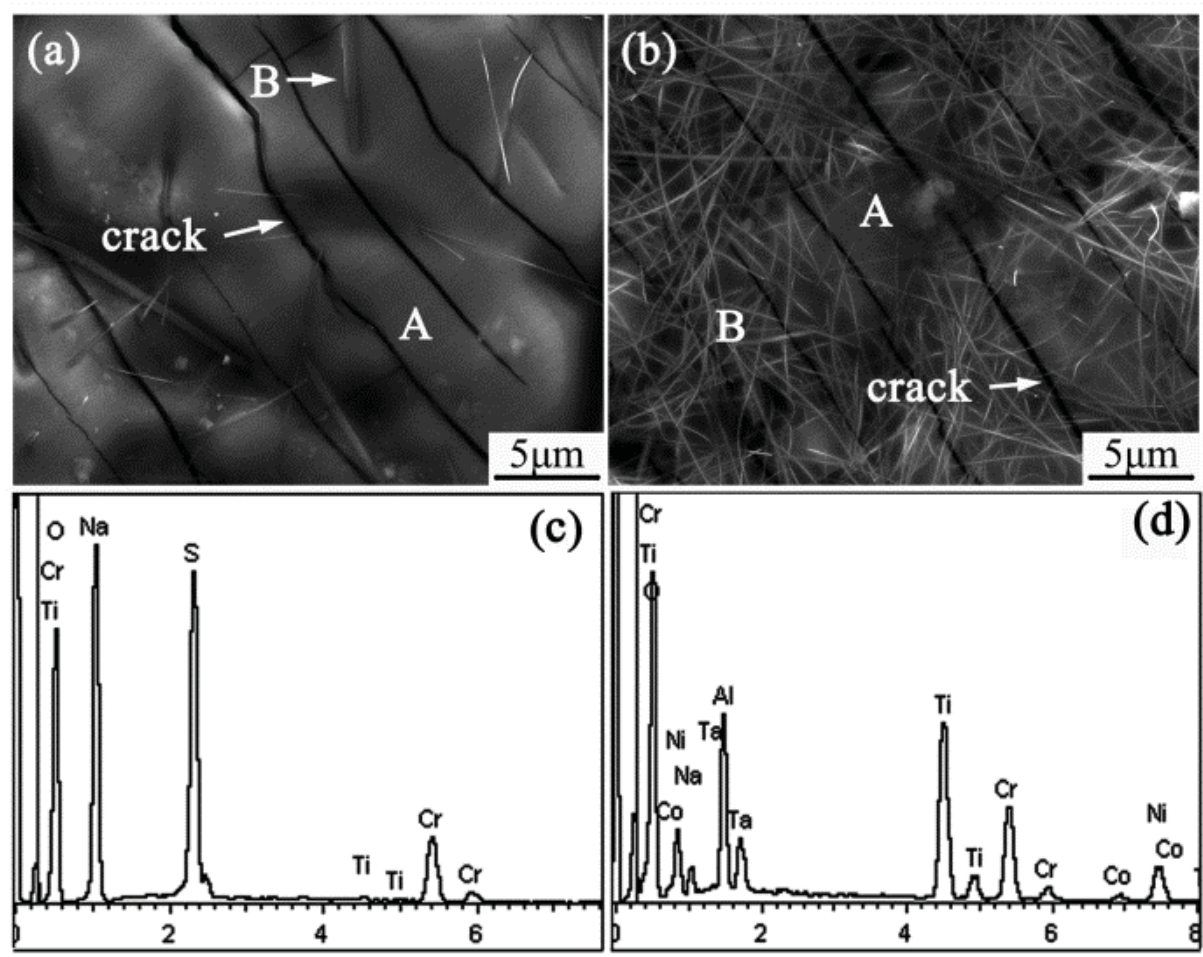

Figure 10 Surface morphologies of the corrosion scales formed on the samples of group II alloys after $240 \mathrm{~h}$ exposure at $900{ }^{\circ} \mathrm{C}$. (a) E7. (b) E71. (c) and (d): EDS results of A and B in (a) and (b).
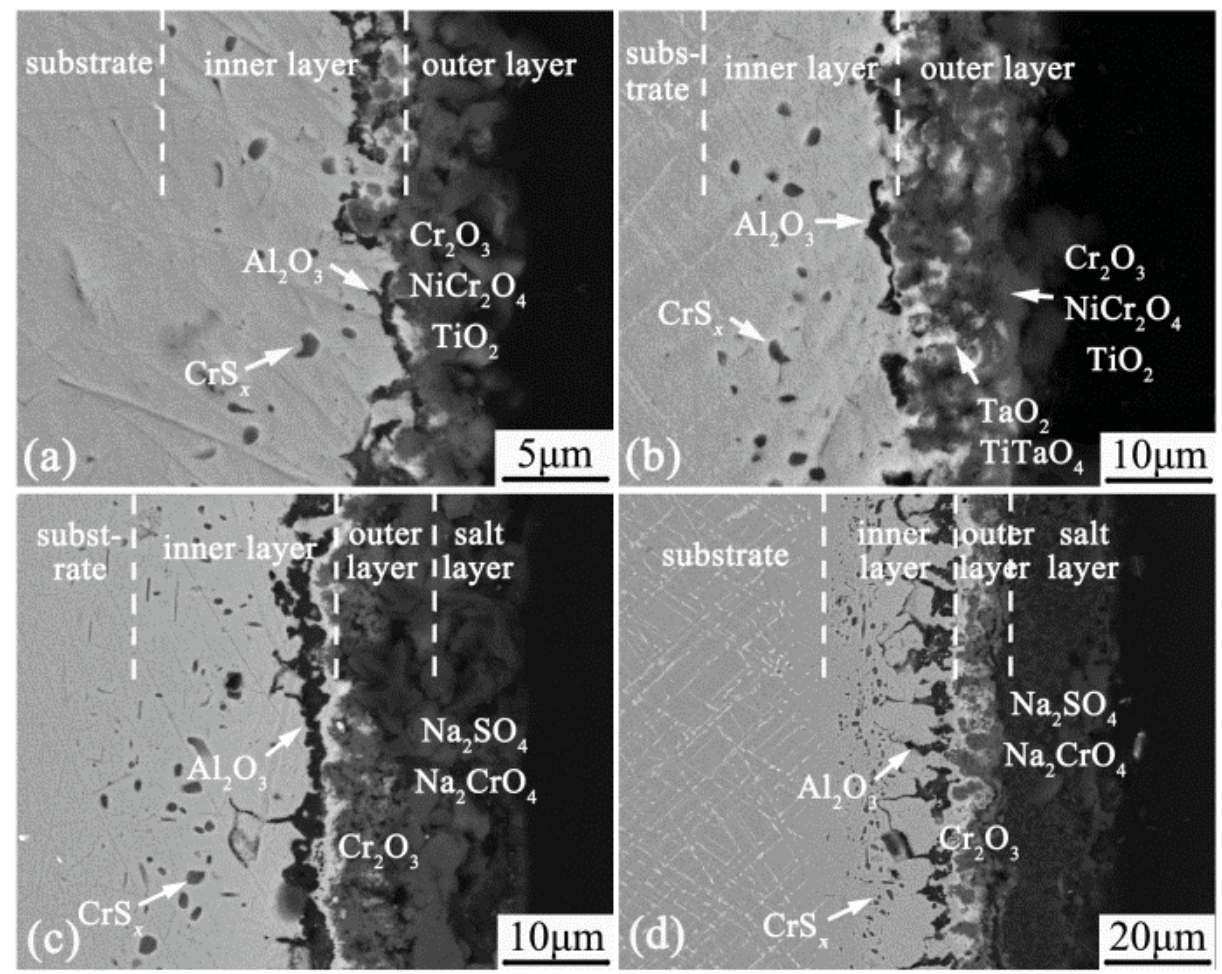

Figure 11 Cross-section morphologies of group II alloys corroded for different time at $900{ }^{\circ} \mathrm{C}$. (a) E7 for $20 \mathrm{~h}$. (b) E71 for $20 \mathrm{~h}$. (c) E7 for 240 h. (d) E71 for 240 h. 
$\underline{\text { Ta Effect in Low Cr Alloys Typical hot corrosion curves of group }}$ III alloys are shown in Fig. 12. In the initial $60 \mathrm{~h}$, the mass changes of the two alloys were similar. After that, E74 experienced rapid mass gain, while the mass change of E76 was still slow. The abrupt mass change of E76 occurred at $140 \mathrm{~h}$. The final mass gain of E74 was almost three-fold that of E76.

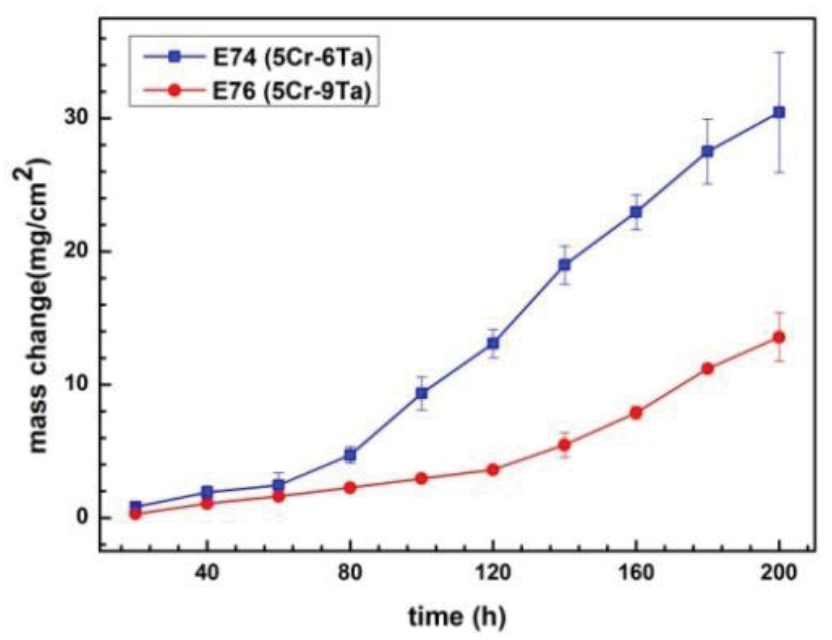

Figure 12 Weight gain versus time curves for group III alloys with a surface coating of $\mathrm{Na}_{2} \mathrm{SO}_{4}$ at $900{ }^{\circ} \mathrm{C}$.

The macroscopic morphologies of the group III alloys are presented in Fig. 13. The corrosion products on E74 started to peel off at $60 \mathrm{~h}$, while the surfaces of E76 were still compact and complete at that time. After $200 \mathrm{~h}$ corrosion, both of the surfaces of the two alloys were loose. Cracking and spallation were remarkable.
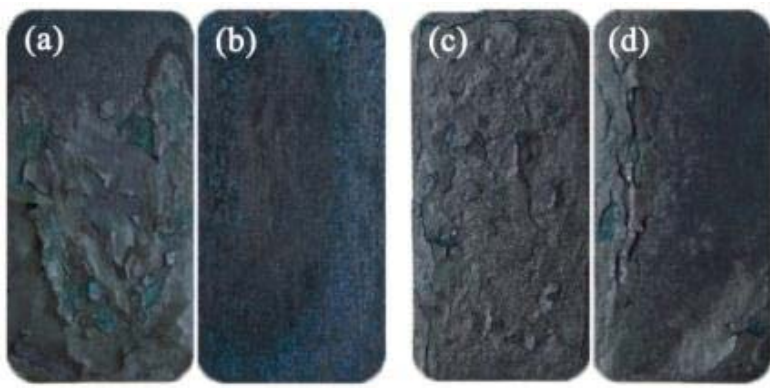

Figure 13 Macroscopic morphologies of the group III alloys corroded at $900{ }^{\circ} \mathrm{C}$ with a surface coating of $\mathrm{Na}_{2} \mathrm{SO}_{4}$. (a) E74 for 60 h. (b) E76 for 60 h. (c) E74 for 200 h. (d) E76 for 200 h.

XRD patterns of the corrosion products formed on E74 are given in Fig. 14. When corrosion time was less than $60 \mathrm{~h}$, the corrosion products did not change significantly. They consist of $\mathrm{Al}_{2} \mathrm{O}_{3}$, $\mathrm{NaTaO}_{3}$ and $\mathrm{NiO}$. After $60 \mathrm{~h}$, peaks of $\mathrm{Al}_{2} \mathrm{O}_{3}$ and $\mathrm{NaTaO}_{3}$ disappeared, only $\mathrm{NiO}$ can be detected. The products formed on E76 can be found in our previous paper [24]. Compared with E74, $\mathrm{Al}_{2} \mathrm{O}_{3}$ and $\mathrm{NaTaO}_{3}$ were still detectable on E76 after $120 \mathrm{~h}$ exposure. $\mathrm{NaTaO}_{3}$ still existed even at $200 \mathrm{~h}$.

Cross section morphologies of E74 are shown in Fig. 15. A three layer structure including an outer oxide layer, an inner oxide layer and an inner sulfide layer was observed. After $20 \mathrm{~h}$ corrosion, a thin $(\mathrm{Co}, \mathrm{Cr}, \mathrm{Al}, \mathrm{Ta})$-doped $\mathrm{NiO}$ layer was formed at the surface of the sample and some $\mathrm{CrS}_{x}$ particles dispersed on the inner depleted zone. With corrosion time increased, both the NiO layer and the sulfide layer became thicker and the inner oxides appeared. As of $80 \mathrm{~h}$, the microstructure and composition of the corrosion scale changed substantially. The outer layer became thicker and porous. Cracks can be seen between the outer layer and the inner layer. Besides the previously existing $\mathrm{CrS}_{x}$ particles, liquid $\mathrm{NiS}_{x}$ network was observed in the inner layer (Fig. $15 \mathrm{~d}$ and $15 \mathrm{~g}$ ). As of $200 \mathrm{~h}$, the entire substrate was corroded (Fig. 15e). Cracks extended from the interface of the porous outer layer and the inner network to the interior of the substrate. A white layer enriched in $\mathrm{Ni}$ and $\mathrm{W}$ can be observed between the outer layer and the inner network (Fig. 15f).

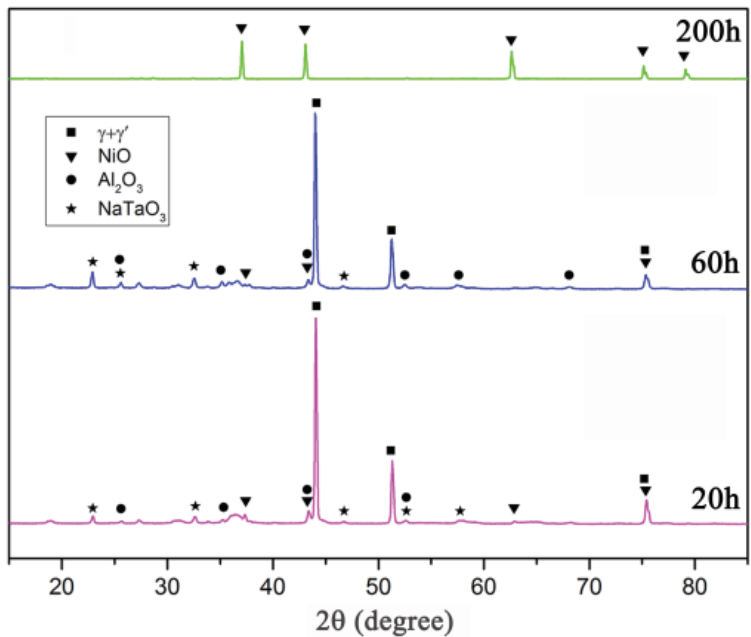

Figure 14 XRD patterns of E74 corroded for different time.

The initial corrosion scale formed on E76 was also composed of an outer doped $\mathrm{NiO}$ layer, an inner $\mathrm{Al}_{2} \mathrm{O}_{3}$ layer and an inner $\mathrm{CrS}_{x}$ layer. With corrosion time increased, the outer $\mathrm{NiO}$ layer thickened. The $\mathrm{Al}_{2} \mathrm{O}_{3}$ layer developed to an $\mathrm{Al}_{2} \mathrm{O}_{3}$-dominant multi-oxides network layer. However, the constituent of the sulfide layer was different from that of $\mathrm{E}_{4}$. $\mathrm{TaS}_{2}$ was formed instead of $\mathrm{NiS}_{x}$. The constituent of the sulfide layer changed in this order: $\mathrm{CrS}_{x} \rightarrow \mathrm{CrS}_{x}+\mathrm{TaS}_{2} \rightarrow \mathrm{TaS}_{2} \rightarrow \mathrm{CrS}_{x}+\mathrm{TaS}_{2}$ $(1.000<x<1.5000)$. The detailed evolutionary process of corrosion scales on E76 was reported in our previous paper [24].

\section{Discussion}

Two temperature regimes of molten sulfate-induced hot corrosion have been studied for nickel and their alloys by previous researchers. At temperatures around $900{ }^{\circ} \mathrm{C}$, pure $\mathrm{Na}_{2} \mathrm{SO}_{4}$ is liquid. Hot corrosion occurred around this temperature is termed as Type-I hot corrosion. However, hot corrosion can also occur below the $\mathrm{Na}_{2} \mathrm{SO}_{4}$ melting point of $884{ }^{\circ} \mathrm{C}$. Rapid attack at temperatures of around $700{ }^{\circ} \mathrm{C}$ is called Type-II hot corrosion. Gas containing $\mathrm{SO}_{3}$ is necessary to develop the liquid $\mathrm{NiSO}_{4}-\mathrm{Na}_{2} \mathrm{SO}_{4}$ which is the corrosion medium of the Type-II hot corrosion of Ni-base alloys [26]. In the present test, $\mathrm{SO}_{3}$ was not introduced in the test system, and the evaporation of $\mathrm{SO}_{3}$ from the $\mathrm{Na}_{2} \mathrm{SO}_{4}$ salt at $750{ }^{\circ} \mathrm{C}$ was not enough for $\mathrm{NiSO}_{4}-\mathrm{Na}_{2} \mathrm{SO}_{4}$ formation. Thus, no significant reaction between the solid salt deposit and the alloys was observed at $750{ }^{\circ} \mathrm{C}$ in the present experiment. The test method should be modified for better investigation of the low temperature hot corrosion behavior of the alloys. As the inlet temperature of IGTs increases, the operating 
temperature of the blades increases. Type-I hot corrosion is thus of high importance. The discussion will focus on hot corrosion at

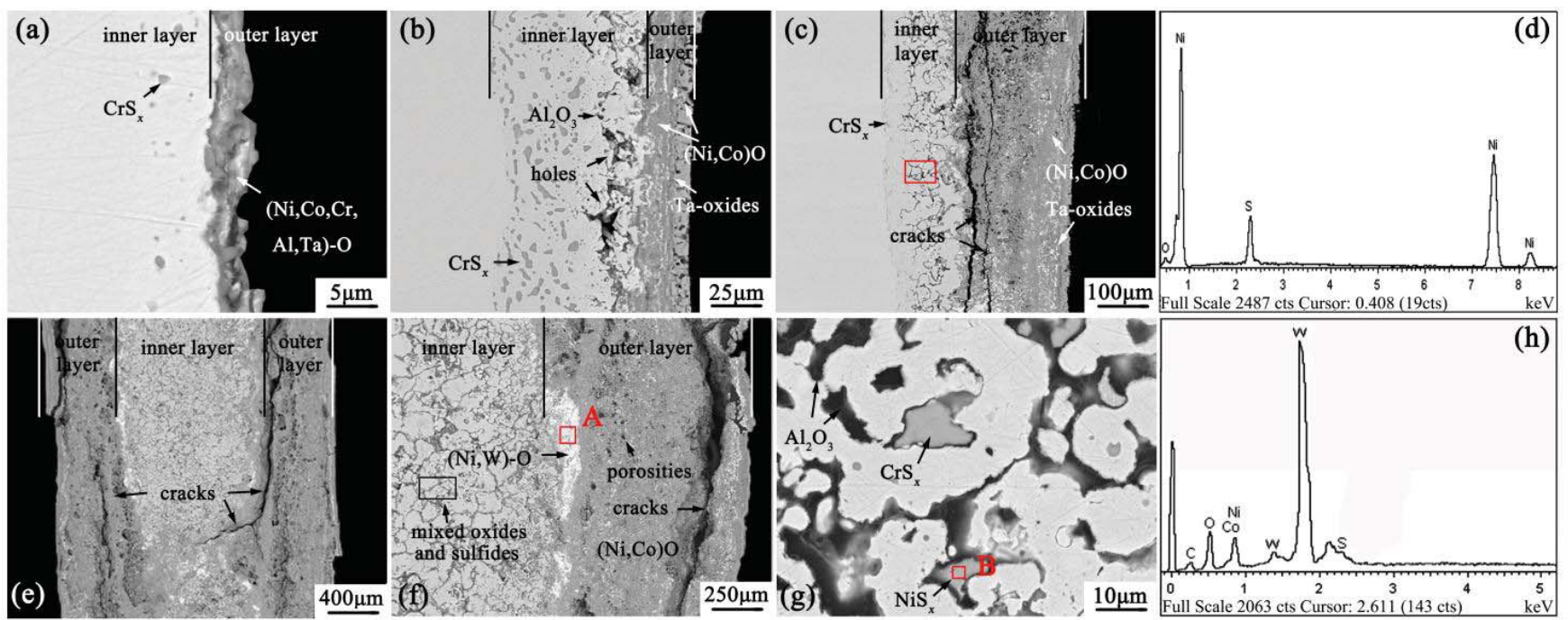

Figure 15 Cross-section morphologies of E74 with different corrosion time. (a), (b), (c) and (e) correspond to the cross-section of $20 \mathrm{~h}, 40 \mathrm{~h}$, $80 \mathrm{~h}$ and $200 \mathrm{~h}$. (f) Higher magnification of the corrosion layers in (e). (g) Higher magnification of the rectangle area in (c). (d) EDS result of the region "B" in (g). (h) EDS result of the region " $A$ " in (f).

In the molten $\mathrm{Na}_{2} \mathrm{SO}_{4}$, the following reaction occurs [23]:

$$
\mathrm{SO}_{4}^{2-}=\mathrm{O}^{2-}+\mathrm{SO}_{3}=\mathrm{O}^{2-}+1 / 2 \mathrm{~S}_{2}+3 / 2 \mathrm{O}_{2}
$$

The hot corrosion of all alloys can be divided into two stages: an initiation stage and a propagation stage. As soon as the coated sample was placed into the furnace, it was oxidized by the molten salt (initiation stage). With corrosion proceeding, the basicity of the salt increases, the dissolution of protective oxides occurred. The degradation process stepped into the propagation stage.

\section{$\underline{\text { Re Effect }}$}

According to the above hot corrosion test results, Re improved hot corrosion resistance of the alloy remarkably. This was probably because $\mathrm{Re}$ addition increased the activity of $\mathrm{Cr}$ in the alloys. As a result, the $\mathrm{Cr}_{2} \mathrm{O}_{3}$-dominant scale on Re-containing alloy was more pure and compact than that on Re-free alloy. The integrated $\mathrm{Cr}_{2} \mathrm{O}_{3}$ layer was more resistant to molten salt and more effective in inhibiting the inward diffusion of oxygen and sulfur. Thus, the formation of protrusions and penetration of salt on Re-containing alloys was postponed, and hot corrosion performance was improved.

For Re-free alloy, the protective oxide scale was easily destroyed. Thus, the released oxygen and sulfur traverse through the scale and caused inner oxidation and sulfidation. Due to the big PBR (Pilling-Bed-Worth Ratio) value of the inner corrosion productions $\left(\mathrm{PBR}_{\mathrm{Al}_{2} \mathrm{O}_{3}}=1.28, \mathrm{PBR}_{\mathrm{CrS}_{x}}=2.8 \sim 3.87\right.$ ), compressive stress was generated in the substrate. Simultaneous deformation of the scale and the substrate then occurred to accommodate the stress. As a result, protrusions were produced and tensile stress was generated in the corrosion scale. Consequently, cracks were produced at tip of the protrusion.

After protrusions and cracks were produced in E1 at $100 \mathrm{~h}$, the alloy experienced rapid corrosion because more corrodents were introduced in the substrate (Fig. 5c). Penetration of salt and fluxing of oxides were remarkable on E1 (Fig. 5d). For E7, protrusions appeared at $160 \mathrm{~h}$, but the mass change of E7 did not increase correspondingly. The inflection points of the curve were $320 \mathrm{~h}$ and $400 \mathrm{~h}$. The overall corrosion kinetics of Re-containing alloy followed multi-stage parabolic law, which was probably because cracks in the outer scale open and close periodically. This phenomenon has also been observed in previous literatures studying the oxidation behavior of $\mathrm{Cr}[27,28]$. This observation may also be attributed to the increased activity of $\mathrm{Cr}$ in $\mathrm{Re}$-containing alloy, which allows more $\mathrm{Cr}$ to diffuse outward to heal the cracks in the protective scale.

\section{$\underline{\text { Ta Effect }}$}

As was well known, $\mathrm{Cr}_{2} \mathrm{O}_{3}$ was the most effective scale to resist Type-I hot corrosion attack [2, 17, 21-23, 29-31]. Thus, the different hot corrosion behavior of alloys containing different $\mathrm{Ta}$ can be related to the evolution of $\mathrm{Cr}_{2} \mathrm{O}_{3}$ scale in the alloys.

In E7 and E71 which have high $\mathrm{Cr}$ content, $\mathrm{Cr}_{2} \mathrm{O}_{3}$ was formed as soon as the samples were put into the furnace. During the whole test, $\mathrm{Cr}$ was sufficient to keep the completeness of the $\mathrm{Cr}_{2} \mathrm{O}_{3}$ scale. $\mathrm{The} \mathrm{Cr}_{2} \mathrm{O}_{3}$ scale can well protect the substrate from hot corrosion. Although small amount of Ta-containing products $\mathrm{TaO}_{2}$ and $\mathrm{TiTaO}_{4}$ were formed in alloys with higher Ta content (E71), they did not affect the corrosion kinetics of alloy.

On the contrary, in E74 and E76 which have medium Cr content, $\mathrm{Cr}$ was insufficient to promote the formation of a continuous $\mathrm{Cr}_{2} \mathrm{O}_{3}$ scale. Instead, sufficient $\mathrm{Ni}$ enabled the formation of a $\mathrm{NiO}$ layer which was susceptible to $\mathrm{Na}_{2} \mathrm{SO}_{4}$-induced hot corrosion [23]. For E76 which has higher Ta content, $\mathrm{NaTaO}_{3}$, which inhibited the formation of $\mathrm{Na}_{2} \mathrm{Mo}(\mathrm{W}) \mathrm{O}_{4}$ and resulted in postponed acidic fluxing [14]. This was formed as soon as the test started and remained throughout the test. The compact oxide layer can act as a diffusion barrier of oxygen. A low oxygen partial pressure 
which permitted the formation of $\mathrm{TaS}_{2}$ was thus established. The detailed discussion of formation of sulfides can be found in our previous paper [24]. Formation of $\mathrm{TaS}_{2}$ led to the release of $\mathrm{Cr}$ due to the decomposition of $\mathrm{CrS}_{x}$, and therefore promoted the formation of $\mathrm{Cr}_{2} \mathrm{O}_{3}$, which can lower the diffusion rate of ions and the oxygen partial pressure in turn. However, for E74, the catastrophic hot corrosion caused by $\mathrm{Na}_{2} \mathrm{Mo}(\mathrm{W}) \mathrm{O}_{4}$ made the outer $\mathrm{NiO}$ layer loose and porous. As a result, the inner oxygen partial pressure was increased. According to Ellingham diagram for sulfides [24, 32] and the M-O-S diagrams [15, 24, 33] produced by HSC chemistry ${ }^{\circledR}$ version $6.0, \mathrm{TaS}_{2}$ formation was not favorable in E74. Because of the large amount of sulfur introduced into the substrate through the porous oxide scale, $\mathrm{Cr}$ was insufficient for sulfide formation. Liquid $\mathrm{NiS}_{x}$ was formed which further increased the corrosion by accelerating the diffusion of ions. After $\mathrm{NiS}_{x}$ was formed, the corrosion rate of E74 increased dramatically. The sample was severely damaged at 200 h.

\section{Summary}

The following conclusions can be drawn based upon analyses of the results obtained in this work:

(1) No significant reaction between the solid salt deposit and the alloys was observed using the present test method without introducing $\mathrm{SO}_{3}$. The hot corrosion behavior of the alloys at 750 ${ }^{\circ} \mathrm{C}$ is similar.

(2) The overall corrosion kinetics of the Re-containing alloy follows multi-stage parabolic law. Re postpones the deformation and cracking of oxide scale and enables the self-healing of cracks in oxide scale. It is probably because Re alters the activities of elements.

(3) Ta promotes the formation of $\mathrm{TaS}_{2}$ besides Ta-containing oxides and spinels, and inhibits the formation of $\mathrm{Na}_{2} \mathrm{Mo}(\mathrm{W}) \mathrm{O}_{4}$ and $\mathrm{NiS}_{x}$. The beneficial effect of Ta is more pronounced in alloys with lower $\mathrm{Cr}$ content.

\section{Acknowledgements}

This work was financially supported by the National High Technology Research and Development Program of China (863 Program) under grant No. 2012AA03A513 and No. 2012AA03A511 and the National Natural Science Foundation of China under grant No. 51171193. The authors are grateful for these supports.

\section{References}

1. G.L. Erickson, "The Development Of The CMSX (R)-11B And CMSX (R)-11C Alloys For Industrial Gas Turbine Application," in Kissinger et al. (eds.), Superalloys 1996, Proc. 8th Int. Symp. On Superalloys, The Metallurgical Society of AIME, 1996, 45-52.

2. R. Burgel et al., "Development Of A New Alloy For Directional Solidification Of Large Industrial Gas Turbine Blades," in K.A. Green et al. (eds.), Superalloys 2004, Proc. 10th Int. Symp. On Superalloys, The Metallurgical Society of AIME, 2004, 25-34.

3. J.S. Zhang et al., "Design And Development Of Hot Corrosion-Resistant Nickel-Base Single-Crystal Superalloys By
The d-Electrons Alloy Design Theory. 1. Characterization Of The Phase-Stability," Metallurgical Transactions a-Physical Metallurgy and Materials Science, 24 (1993) 2443-2450.

4. I. Okada et al., "Development Of Ni-Base Superalloy For Industrial Gas Turbine," in K.A. Green et al. (eds.), Superalloys 2004, Proc. 10th Int. Symp. On Superalloys, The Metallurgical Society of AIME, 2004, 707-712.

5. F.S. Pettit and G.H. Meier, "Oxidation And Hot Corrosion Of Superalloys," in Superalloys 1984, Proc. 5th Int. Symp. On Superalloys, The Metallurgical Society of AIME, 1984, 651-687.

6. K.R. Peters, D.P. Whittle, and J. Stringer, "Oxidation And Hot Corrosion Of Nickel-Based Alloys Containing Molybdenum," Corrosion Science, 16 (1976) 791-804.

7. T.S. Sidhu, R.D. Agrawal, and S. Prakash, "Hot Corrosion Of Some Superalloys And Role Of High-Velocity Oxy-Fuel Spray Coatings-A Review," Surface and Coatings Technology, 198 (2005) 441-446.

8. K. Matsugi et al., "Alloying Effects Of $\mathrm{Cr}$ And Re On The Hot-Corrosion Of Nickel-Based Single-Crystal Superalloys Coated With $\mathrm{A} \mathrm{Na}_{2} \mathrm{SO}_{4}-\mathrm{NaCl}$ Salt," Tetsu to Hagane-Journal of the Iron and Steel Institute of Japan, 78 (1992) 821-828.

9. Y.M. K. Matsugi, M. Morinaga, and N. Yukawa, "Realistic Advancement For Nickel-Based Single Crystal Superalloys By The d-Electrons Concept," in S.D. Antolovich et al. (eds.), Superalloys 1992, Proc. 7th Int. Symp. On Superalloys, The Metallurgical Society of AIME, 1992, 307-316.

10. M. Moniruzzaman et al., "Alloy Design Of Ni-Based Single Crystal Superalloys For The Combination Of Strength And Surface Stability At Elevated Temperatures," ISIJ International, 43 (2003) 1244-1252.

11. P. Caron and T. Khan, "Evolution Of Ni-Based Superalloys For Single Crystal Gas Turbine Blade Applications," Aerospace Science and Technology, 3 (1999) 513-523.

12. N. Czech, F. Schmitz, and W. Stamm, "Improvement Of MCrAlY Coatings By Addition Of Rhenium," Surface and Coatings Technology, 68 (1994) 17-21.

13. A.W.I. Gurrappa, H.L. Du, and J. Burnell-Gray, "Hot Corrosion Behavior of Newly Developed Nickel Based Superalloy and Comparison with other Alloys," ECS Transactions, 24 (2008) 105-115.

14. G.C. Fryburg, C.A. Stearns, and F.J. Kohl, "Mechanism Of Beneficial Effect Of Tantalum In Hot Corrosion Of Nickel-Base Superalloys," Journal of the Electrochemical Society, 124 (1977) 1147-1148.

15. G.C. Fryburg et al., "Chemical-Reactions Involved In The Initiation Of Hot Corrosion Of B-1900 And NASA-TRW VIA," Journal of the Electrochemical Society, 129 (1982) 571-585.

16. G.C. Fryburg, F.J. Kohl, and C.A. Stearns, "Chemical-Reactions Involved In The Initiation Of Hot Corrosion 
Of IN-738," Journal of the Electrochemical Society, 131 (1984) 2985-2997.

17. Y. Murata et al., "Alloying Effects On Surface Stability And Creep Strength Of Nickel Based Single Crystal Superalloys Containing 12 mass $\%$ Cr," in T.M. Pollock et al. (eds.), Superalloys 2000, Proc. 9th Int. Symp. On Superalloys, The Metallurgical Society of AIME, 2000, 285-294.

18. F.F. Han et al., "Influence Of Ta Content On Hot Corrosion Behaviour Of A Directionally Solidified Nickel Base Superalloy," Journal of Alloys and Compounds, 619 (2015) 102-108.

19. J.S. Zhang at al., "Design And Development Of Hot Corrosion-Resistant Nickel-Base Single-Crystal Superalloys By The d-Electrons Alloy Design Theory. 2. Effects Of Refractory-Metals $\mathrm{Ti}$, Ta, And $\mathrm{Nb}$ On Microstructures And Properties," Metallurgical Transactions a-Physical Metallurgy and Materials Science, 24 (1993) 2451-2464.

20. H. Cui et al., "Hot Corrosion Behavior Of Ni-Based Superalloy With High Cr Contents - Part 1. Experimental Study," Journal of University of Science and Technology Beijing (English Edition), (1996) 90+84-89.

21. N. Otsuka and R.A. Rapp, "Effects Of Chromate And Vanadate Anions On The Hot Corrosion Of Preoxidized Ni By A Thin Fused $\mathrm{Na}_{2} \mathrm{SO}_{4}$ Film At 900-Degrees-C," Journal of the Electrochemical Society, 137 (1990) 53-60.

22. R.A. Rapp, "Hot Corrosion Of Materials: A Fluxing Mechanism?," Corrosion Science, 44 (2002) 209-221.

23. J.A. Goebel and F.S. Pettit, " $\mathrm{Na}_{2} \mathrm{SO}_{4}$-induced Accelerated Oxidation (Hot Corrosion) Of Nickel," Metallurgical Transactions, 1 (1970) 1943-1954.

24. J.X. Chang et al., "Role Of Tantalum In The Hot Corrosion Of A Ni-Base Single Crystal Superalloy," Corrosion Science, 98 (2015) 585-591.

25. D.J. Young, W.W. Smeltzer, and J.S. Kirkaldy, "Nonstoichiometry And Thermodynamics Of Chromium Sulfides," Journal of the Electrochemical Society, 120 (1973) 1221-1224.

26. K.L. Luthra and D.A. Shores, "Mechanism Of $\mathrm{Na}_{2} \mathrm{SO}_{4}$ Induced Corrosion At 600-Degrees-C-900-Degrees-C," Journal of the Electrochemical Society, 127 (1980) 2202-2210.

27. P. Kofstad and K.P. Lillerud, "On High-Temperature Oxidation Of Chromium. 2. Properties Of $\mathrm{Cr}_{2} \mathrm{O}_{3}$ And The Oxidation Mechanism Of Chromium," Journal of the Electrochemical Society, 127 (1980) 2410-2419.

28. K.P. Lillerud and P. Kofstad, "On High-Temperature Oxidation Of Chromium. 1. Oxidation Of Annealed, Thermally Etched Chromium At 800-Degrees-1100-Degrees-C," Journal of the Electrochemical Society, 127 (1980) 2397-2410.

29. N.S. Bornstei and M.A. Decresce, "Role Of Sodium In Accelerated Oxidation Phenomenon Termed Sulfidation," Metallurgical Transactions, 2 (1971) 2875-2883.
30. N.S. Bornstei, M.A. Decresce, and H.A. Roth, "Relationship Between Relative Oxide Ion Content of $\mathrm{Na}_{2} \mathrm{SO}_{4}$, Presence Of Liquid-Metal Oxides And Sulfidation Attack," Metallurgical Transactions, 4 (1973) 1799-1810.

31. J.A. Goebel, F.S. Pettit, and G.W. Goward, "Mechanisms For The Hot Corrosion Of Nickel-Base Alloys," Metallurgical Transactions, 4 (1973) 261-278.

32. S.R. Shatynski, "Thermochemistry Of Transition-Metal Sulfides," Oxidation of Metals, 11 (1977) 307-320.

33. M. Mobin and A.U. Malik, "Studies On The Interactions Of Transition Metal Oxides And Sodium Sulfate In The Temperature Range 900-1200 K In Oxygen," Journal of Alloys and Compounds, 235 (1996) 97-103. 